\title{
COOPERAÇÃO INTERINSTITUCIONAL: INDICADORES DE RESULTADOS DE INTERAÇÕES DE PESQUISADORES VISITANTES EM INSTITUIÇỔES DE ENSINO E PESQUISA
}

\author{
INTERINSTITUTIONAL COOPERATION: RESULTS \\ INDICATORS OF INTERACTIONS OF VISITING \\ RESEARCHERS IN HIGHER EDUCATION AND RESEARCH \\ INSTITUTIONS
}

Fabrício Baron Mussi

Usina Hidrelétrica de Itaipu - PR - Brasil

Blasius Silvano Debald

Faculdade União das Américas - PR - Brasil

\begin{abstract}
Resumo: O presente trabalho possui como objetivo definir uma proposta de caracterização de indicadores de resultados de pesquisa conjunta. Para proceder com a elaboração dessa proposta, utilizaram-se os direcionamentos da literatura acerca da cooperação interinstitucional, de intercâmbios e indicadores. Foram selecionados dez casos para avaliação, tendo a investigação percorrido o seguinte caminho: visitas às instituições receptoras localizadas em diversas cidades; visitas aos locais de trabalho onde os projetos submetidos estavam sendo desenvolvidos; entrevistas com os coordenadores dos projetos e com os pesquisadores visitantes; entrevistas com outras pessoas envolvidas; leitura de documentos adquiridos durante a coleta de dados primários e dos projetos aprovados e; por fim, novo contato com os entrevistados para esclarecer eventuais dúvidas. A pesquisa, do ponto de vista teórico, contribuiu com o desenvolvimento de uma proposta de indicadores para caracterização e avaliação de cooperações interdisciplinares entre pesquisadores de universidades e institutos de pesquisa distintos. Entre as contribuições práticas, pode-se mencionar o auxílio a instituições de fomento no aperfeiçoamento de editais de apoio ao desenvolvimento científico e tecnológico, bem como o aprimoramento dos sistemas de avaliação referentes a essas ações.
\end{abstract}

Palavras-chave: Cooperação interinstitucional. Indicadores. Pesquisadores visitantes.

Abstract: This paper aims to define a proposition for a characterization of indicators applicable to evaluate joint research results. In order to do that, literature on interinstitutional cooperation, exchange programs and indicators was assessed, and its guidelines, adopted. Ten cases were selected for evaluation, and the following procedures undertaken: visits to receptor institutions in several cities; visits to workplace where the subjected projects were being developed; interviews with project managers and visiting researchers; interviews with other personnel; review of the approved projects' official documentation collected during the previous steps; and a new contact with the respondents to clarify eventual doubts. Theoretically, this research contributes to the development of a proposal of a set of indicators to characterize and evaluate interdisciplinary cooperation between researchers from universities and distinct research institutes. Practical contributions to be mentioned are the information gathered that can help promotion agencies to improve their supporting edicts offered to scientific and technological development, as well as upgrading their evaluation systems regarding such actions.

Key words: Interinstitutional cooperation. Indicators. Visiting researchers. 


\section{Introdução}

A necessidade de mensurar os impactos quantitativos e qualitativos de ações e investimentos realizados em Ciência, Tecnologia e Inovação na realidade econômica de um país constitui premissa essencial para o controle e acompanhamento do desenvolvimento de uma nação. A complexidade da interrelação entre as esferas social, econômica, política e cultural que compõem e sustentam a estrutura de um país é refletida pela abundância de indicadores existentes para caracterizar, captar, mensurar e diagnosticar a situação vigente de um ou de vários setores de uma economia, incorrendo - por vezes - em falta de consenso, robustez e clareza (FURTADO; QUEIROZ, 2002). A temática dos indicadores de Ciência, Tecnologia e Inovação carece de trabalhos mais avaliativos, ou que ao menos, retratem a situação em que as realidades estudadas realmente se encontram (HERRLEIN PEREIRA, 2001). Exceções são as propostas de Viotti e Macedo (2003) e Martínez e Albornoz (1998), este último não restrito ao cenário geopolítico brasileiro.

No tocante à esfera acadêmica, as pesquisas sobre os meios aplicados para acelerar e consolidar a interação entre universidades, institutos de pesquisa e empresas têm variado quanto à natureza. Algumas destas investigações são feitas com o propósito de criar relatórios, de interesse principalmente do governo, ou com o objetivo de fazer auditorias sobre a forma e frequência da interação, ou seja, se a interação acontece por intermédio de uma consultoria, de um contrato de pesquisa, ou de outro mecanismo. Uma das principais fontes de estímulo de interações acadêmicas, para Aguiar (2007), é representada pelas crescentes e contínuas empreitadas de órgãos de fomento na esfera federal e na esfera estadual (principalmente por intermédio das Fundações de Amparo a Pesquisa - FAP). Nesse contexto, pouca atenção tem sido atribuída ao relacionamento entre diferentes universidades. As possibilidades de cooperação entre estas e a avaliação de seus resultados carecem de estudos analíticos e prescritivos que avaliem e sugiram indicadores que caracterizem interações - de natureza interdisciplinar-, como, por exemplo, os intercâmbios.

A partir da exposição, o presente estudo tem como finalidade compor uma proposta de conjunto de indicadores de resultados de pesquisa. A iniciativa empreendida utiliza o lançamento de um edital de apoio financeiro à vinda de pesquisadores/professores visitantes nas universidades e institutos de pesquisa como lócus para avaliação e fundamento para as proposições. Foram investigados dez casos de projetos aprovados na primeira e segunda chamada de um edital e, a partir dessa avaliação (MUSSI e SEGATTO, 2010), elaborou-se uma proposta de conjunto de indicadores capazes de representar os resultados dessa experiência.

A estrutura do texto inicia-se com a revisão da literatura sobre o tema, partindo-se de um contexto mais abrangente de definição do termo "indicador" até as especificidades e limitações dos indicadores de resultados usados para avaliação de atividades desenvolvidas nas universidades. Posteriormente, demonstram-se os procedimentos metodológicos realizados e contextualiza-se o edital que serviu de base para o estudo, bem como os casos analisados. Por fim, 
empreende-se uma proposta de caracterização da vinda de pesquisadores visitantes nas instituições estudadas. Na última seção, seguem as considerações finais, contribuições oriundas deste trabalho e as limitações da pesquisa.

\title{
1 Cooperação e Intercâmbios: contextualização da literatura
}

Para que o processo de cooperação conjunta e de aprendizagem ocorram, tanto na esfera empresarial, quanto no âmbito acadêmico é necessário fomentar um ambiente propício às relações entre as várias instituições/atores que um sistema de inovação abrange (LUNDVALL, 1992; ETZKOWITZ; LEYDESDORFF, 2000). Enquanto ampliam-se as possibilidades de discussão na literatura sobre o relacionamento entre empresas, institutos de pesquisa e universidades, especialmente no tocante à forma, gestão e avaliação desses relacionamentos (FAULKNER; SENKER; VELHO, 1995; SPENDER, 1999; SCHIBANY; POLT, 2001; WRIGHT, 2008), pouca atenção têm sido atribuída às questões internas das universidades e as interações destas com outras e com os institutos de pesquisa. Entre tais questões, destaca-se o intercâmbio científico que, segundo Gatti (2005, p.124-125),

\begin{abstract}
processa-se não só por congressos e reuniões científicas de diversas naturezas, mas também por mecanismos como estágios, professores visitantes, desenvolvimento de projetos interinstitucionais, participações em redes de pesquisadores em temas correlatos, participações em grupos de pesquisa, etc [...] esse intercâmbio pode desenvolver-se tanto em nível regional, nacional ou internacional, via programas básicos das agências de fomento à pesquisa, ou via programas de intercâmbio da Coordenação de Aperfeiçoamento de Pessoal de Nível Superior [...] e ainda por convênios bilaterais mantidos por algumas universidades com financiamento próprio.
\end{abstract}

Atualmente, algumas condições são essenciais para realização de investigações e para o avanço dos conhecimentos científicos. Destacam-se a necessidade de intercomunicação dos pesquisadores com seus pares; o trabalho em equipe; as redes de trocas de ideias, disseminação de propostas e achados de investigação; e a consolidação de grupos de referência temática (ANPED, 1984; GATTI, 2005).

Nas ciências sociais aplicadas, a literatura existente trata principalmente das relações entre universidades e empresas, sendo que na busca por referencial não foi possível identificar um maior número de colocações acerca de cooperações entre duas universidades (Cooperação $U / U$ ), e entre universidades e institutos de pesquisa (Cooperação U/IPs). Isso representa a existência de uma lacuna no conhecimento sobre o tema. Uma iniciativa para preencher este espaço foi empreendida por Rossoni e Guarido-Filho (2007), Rossoni e Hocayen-da-Silva (2008) e Rossoni, Hocayen-da-Silva e Ferreira Junior (2008), os quais analisaram, por meio de métodos quantitativos, a cooperação entre instituições e 
pesquisadores em algumas áreas do campo da administração e dos estudos organizacionais.

Entende-se que, apesar de existirem especificidades nas relações com diferentes configurações de atores, no geral essas relações possuem a mesma finalidade, originam-se praticamente da mesma forma e transcorrem de forma semelhante. Desse modo, entende-se ser válido assumir que o referencial apresentado, apesar de estar centrado nas contribuições relativas às cooperações universidade-empresa, é coerente para os demais contextos, visto que a utilização de conceitos comuns ou taxonomias já conhecidas podem auxiliar a construir o conjunto de indicadores que se pretende.

\subsection{Indicadores: conceito e características}

Os indicadores são definidos por Brisolla (2004, p. 213) como

[...] pistas, indícios, trilhas que seguimos em busca da compreensão dos nexos que relacionam variáveis responsáveis por fenômenos econômicosociais, políticos e culturais que afetam a vida em sociedade. Mais do que estatísticas isoladas, os indicadores são variáveis relativas, organizadas em grupos, e pretendem formar um conjunto coerente que represente um sistema em suas múltiplas determinações. São, portanto, reflexos de conceitos e, como tais, voláteis e em constante transformação, acompanhando o avanço do conhecimento da realidade que pretendem mimetizar.

O conceito de 'indicador' compreende algo que, por sua natureza, é dinâmico, dado o aspecto multifacetado da realidade a qual este tenta representar, ao mesmo tempo em que será uma simplificação da realidade, sem capacidade de representá-la em sua integralidade. Os indicadores, enquanto meios para se aferir aspectos de um determinado cenário, não estão isentos de certa relatividade - por mais que se associe a estes um caráter numérico absoluto em virtude da lógica quantitativista que sua utilização estatística apregoa. Igualmente tentam captar, como salienta o conceito acima, fenômenos de cunho social, político e cultural, de modo que por estes mesmos também pode ser influenciado.

Embora tais constatações possam sugerir a invalidez da ideia de indicadores como sendo maneiras objetivas e confiáveis de se representar e medir uma realidade, é relevante mencionar que tal pressuposto não se sustenta na literatura pesquisada (VIOTTI; MACEDO, 2003), uma vez que será o rigor epistemológico, teórico e metodológico da aplicação de um determinado indicador (ou conjunto de indicadores) que definirá a validade dos seus apontamentos e/ou constatações (BABBIE, 1992; HAIR JR. et al, 2005). Conforme argumentam Lastres, Legey e Albagli (2003, p. 537)

com o desenvolvimento de indicadores, procura-se reduzir fenômenos complexos a fórmulas simplificadas e facilmente comunicáveis e mensuráveis, passíveis de agregações, comparações e extrapolações. Esses indicadores são geralmente destinados à tomada de decisão e ao estabelecimento de estratégias e prioridades, o que requer que sejam de 
fácil compreensão, numericamente limitados e baseados em dados disponíveis ou passíveis de serem coletados em tempo hábil e a custos razoáveis. Portanto, quanto mais claros os conceitos que descrevem uma dada realidade ou situação, menor a distorção dos instrumentos que visam representá-la e mensurá-la.

No âmbito das Ciências Sociais, a elaboração e utilização de indicadores para levantar, mensurar e avaliar fenômenos, que suscitam problemas específicos de pesquisa, já se encontra notoriamente absorvida e estabelecida nas áreas que compõem o referido campo do saber. Está presente, por exemplo, na Economia, Administração, Sociologia e Ciência Política, propiciando inclusive mais robustez a movimentos de conversação e integração interdisciplinar (BABBIE, 1992; BRISOLLA, 2004). Partindo dessa mencionada pluralidade, apresentam-se na seção subsequente alguns exemplos de indicadores construídos, utilizados e associados especificamente a questões de investimentos em Ciência, Tecnologia e Inovação (C.T\&l), são eles:

a) IBI - Índice Brasileiro de Inovação: tem por objetivo ordenar as empresas de acordo com o seu grau de inovatividade dentro do setor, restringindo o escopo desse índice ao plano industrial. O referido "grau de inovatividade" do IBI seria então construído a partir da "[...] conjugação de elementos os quais podem ser capturados por meio de indicadores de insumo e de produto" (FURTADO; QUADROS; QUEIROZ, 1998, p. 26). As críticas a este índice referem-se a: ausência de explicações metodológicas no que tange à aplicação do mesmo para a mensuração dos impactos financeiros da inovação; a imprecisão sobre como aplicar tal índice de forma intersetorial; e a falta de detalhamento sobre os cálculos dos quocientes que compõem sua fórmula;

b) PINTEC - Pesquisa de Inovação Tecnológica: configura-se como fonte utilizada nacionalmente para a questão dos indicadores de C,T\&I. Seu escopo compreende as atividades das indústrias extrativistas, de transformação, e os serviços de alta intensidade tecnológica, como telecomunicações, informática e P\&D, em um universo de pesquisa da ordem de 72.005 empresas. Em termos teórico-metodológicos, a PINTEC utiliza o Manual de Oslo - elaborado e adotado na União Europeia para a avaliação das atividades de C,T\&I desse bloco econômico;

c) Índices do Ministério da Ciência e Tecnologia: a lista de indicadores de C,T\&I considerada pelo Ministério da Ciência e Tecnologia brasileiro (2008) também abarca uma série distinta e abrangente de índices, porém não se situando apenas na esfera industrial ou empresarial. Ênfase também é atribuído às questões educacionais em diferentes níveis (básico, médio, profissionalizante, superior e pós-graduação), contemplando assim escolaridade, produção científica da nação, a questão das patentes, bolsas de formação, quantidade e natureza de cursos lato sensu e stricto sensu existentes no país. 
A seguir, discute-se o emprego de indicadores e avaliação de ações realizadas no âmbito acadêmico, sendo, na sua maioria, avaliações de ações conjuntas entre universidades e empresas.

\subsection{Avaliação de resultados e indicadores com foco nas interações entre empresas} e universidades (E/U)

Os projetos de pesquisa realizados em conjunto por universidades e empresas podem gerar diferentes resultados, tanto no âmbito da satisfação (bom ou ruim), do tempo de abrangência (curto ou longo prazo) e da possibilidade de mensuração (tangível ou intangível) (SEGATTO, 1996).

Nessa perspectiva, a conclusão positiva de um processo de cooperação pode, em primeira instância, despertar nos envolvidos uma boa impressão no que diz respeito ao comportamento de seu parceiro, bem como o desejo de continuidade imediata da parceria. Tal fato representa, assim, a possibilidade de uma longa trajetória de projetos bem-sucedidos (SEGATTO-MENDES; SBRAGIA, 2002). Quanto à análise dos resultados no longo prazo, Dossa e Segatto (2010) afirmam que estes dependem dos parceiros envolvidos, da especificidade do projeto que está sendo executado e do desenvolvimento da cooperação propriamente dito.

Embora os indicadores de resultado intangíveis complementem a mensuração dos resultados de um processo de cooperação, uma questão que deve ser considerada refere-se ao modo como tais indicadores podem ser, na prática, operacionalizados. Em alguns casos poder-se-ia, inclusive, questionar como (ou seja, com respaldo em que método) estabelecer uma relação de causa e efeito entre o processo de cooperação e alterações subsequentes nos pontos sugeridos por Cyert e Goodman (1997). A subseção seguinte explora as críticas ao uso de determinados indicadores de ciência e tecnologia de modo geral e indicadores de resultado nos processos cooperativos interinstitucionais, de modo particular. Não obstante alguns desses indicadores sejam usados no presente estudo, cabe reconhecer suas limitações, seja qual for sua natureza.

\subsection{Limitações apontadas na literatura sobre indicadores de C\&T e acadêmicos}

Usando as contribuições de Nelson (1993) sobre as dificuldades de verificarem os resultados de atividades de pesquisa realizadas na forma de cooperação (e, em especial, de P\&D), indo além dos indicadores considerados clássicos - artigos publicados e patentes - Aguiar (2007) explora os entraves encontrados na observação dos reflexos das atividades cooperativas para a economia e para a sociedade. Com relação a esta última questão, focando de maneira particular o cenário brasileiro no tocante a avaliação de ciência e tecnologia, Aguiar (2007) aponta as seguintes considerações:

a) Ausência de um sistema amplamente aceito e que seja consistente, conceitualmente e metodologicamente, de avaliação e comparação de indicadores de resultados científicos, tecnológicos, econômicos e sociais; 
b) Problemas para apontar com exatidão resultados que estão relacionados, de forma evidente, a um único projeto;

c) Debilidade da cultura de aferição de resultados nas instituições de ensino e pesquisa, comprometendo assim a emersão e continuidade de ações para montagem de sistemas de avaliação de resultados;

d) Necessidade de uma metodologia que permita comparar resultados de projetos desenvolvidos 'em rede' com projetos executados individualmente.

Em termos gerais, Albuquerque et al. (2002) e Viotti e Macedo (2003) criticam o uso de indicadores sem que se façam as devidas ponderações que as circunstâncias da pesquisa requerem. Nessas ponderações deveriam ser abarcadas as particularidades da pesquisa em si, da região onde foi desenvolvida e do respectivo campo de conhecimento. Uma das formas de minimizar tais limitações, seguindo a sugestão de Loures e Figueiredo (2006), seria buscar outros indicadores que não se restringissem aos números agregados. Nesse contexto, a inclusão de indicadores qualitativos consiste numa alternativa.

Uma vez que indicadores, com limitações ou não, são obtidos, surge a questão de como esses são utilizados. Velho (1998) critica o baixo uso dos indicadores de C\&T para tomada de decisões. Segundo essa autora, investe-se muito na obtenção de informações quantitativas (como a construção de indicadores) que são pouco utilizadas, tanto no Brasil, quanto em países desenvolvidos. Entre os motivos levantados para tal ocorrência, pode-se destacar:

a) Os indicadores são usados como um respaldo ex-post de decisões políticas. Salienta-se que, por vezes, aspectos qualitativos, ainda que menos objetivos, são mais considerados que informações quantitativas;

b) Questionamentos de caráter conceitual podem restringir-se à análise da ciência que, de certa forma, está atrelada a objetivos sociais e econômicos;

c) Há complicações metodológicas na elaboração de indicadores, mesmo a partir dos dados compilados corretamente, de maneira que sejam comparáveis, constituam séries históricas, tenham um bom nível de agregação de dados e sejam atuais.

Observa-se que as principais restrições, no âmbito dos indicadores de ciência e tecnologia, estão atreladas às questões conceituais e metodológicas. Entre os indicadores, encontram-se parcialmente identificados alguns daqueles relacionados com as atividades da universidade. Nesta última, para realizar avaliações e definir políticas, como em outros setores, os indicadores representam ferramentas utilizadas com maior ou menor intensidade. Eles são aplicados para medir insumos e resultados, tomar decisões e definir planos. Conforme MaciasChapula (1998) salienta, maior atenção tem sido ofertada aos indicadores de resultado da atividade acadêmica do que para os de insumo (verbas e pessoal), especialmente por conta das discussões e redefinições das relações entre o progresso econômico e social e as contribuições que se espera da ciência e da tecnologia.

Bicalho-Moreira e Ferreira (2000) separam os indicadores acadêmicos em indicadores de (1) produção científica e de (2) produção tecnológica. O primeiro 
baseia-se quase predominantemente em publicações especializadas em forma de artigos científicos publicados em revistas especializadas, livros e trabalhos completos publicados em anais de congressos. O segundo refere-se aos novos produtos e processos, número de patentes e número de citações de patentes. Com o foco no primeiro dos indicadores acadêmicos (a produção científica), o quadro a seguir apresenta algumas das suas limitações.

Quadro 1. Principais críticas aos indicadores relacionados à produção científica.

\begin{tabular}{|c|c|c|}
\hline Autor & Aspectos salientados & Crítica \\
\hline $\begin{array}{l}\text { Mostafa e } \\
\text { Maranon } \\
(1993, \\
\text { p.28); } \\
\text { Mezan } \\
(2010)\end{array}$ & $\begin{array}{lrr}\text { Excesso } & \text { de } & \text { foco } \\
\text { quantidade } & \text { de } \\
\text { publicações. } & & \end{array}$ & $\begin{array}{l}\text { "Preocupação relacionada ao fato de os indicadores de } \\
\text { atividades de C\&T (neste caso, de produção científica) } \\
\text { estarem, sobremaneira, centrados no número de } \\
\text { publicações. Para os autores, tal evento pode estar } \\
\text { levando todos os cientistas a estarem vivendo uma fase na } \\
\text { qual publica-se por publicar'. Produz-se, por produzir, em } \\
\text { uma dinâmica que se consome bem menos do que se } \\
\text { produz. [...] a produção com um fim em si mesma". }\end{array}$ \\
\hline $\begin{array}{l}\text { Mostafa e } \\
\text { Maranon } \\
\text { (1993) }\end{array}$ & $\begin{array}{l}\text { (1) Opção pelos veículos } \\
\text { de publicação que } \\
\text { demandam menos } \\
\text { tempo. (2) Dificuldade } \\
\text { em localizar tais } \\
\text { publicações. }\end{array}$ & $\begin{array}{l}\text { As publicações ditas (pelos autores) "cinzentas", ou "não } \\
\text { convencionais" - relatórios, teses, comunicações } \\
\text { apresentadas em eventos publicadas (ou não) em anais - } \\
\text { estão aumentando em número e relevância por conta da } \\
\text { agilidade maior possibilitada pelos seus veículos de } \\
\text { divulgação (eventos) em contraposição ao tempo gasto } \\
\text { com o processo de submissão, avaliação, aceitação e } \\
\text { publicação de artigos em revistas especializadas ou } \\
\text { "journals". Uma dificuldade apontada com relação à } \\
\text { literatura não convencional é a dificuldade de sua } \\
\text { localização nos canais habituais, tornando difícil a sua } \\
\text { identificação e aquisição. }\end{array}$ \\
\hline $\begin{array}{l}\text { Spinak } \\
\text { (1998) }\end{array}$ & $\begin{array}{l}\text { Dificuldade encontrada } \\
\text { nas publicações } \\
\text { pertencentes aos países } \\
\text { em desenvolvimento } \\
\text { para se adequarem às } \\
\text { avaliações bibliométricas } \\
\text { internacionais. }\end{array}$ & $\begin{array}{l}\text { Os mecanismos utilizados pelo ISI (Institute of Science } \\
\text { Information) nas avaliações bibliométricas também } \\
\text { constituem um motivo de preocupação, uma vez que este } \\
\text { instituto faz uso de instrumentos adequados para medir a } \\
\text { ciência do mainstream, agindo parcialmente na seleção } \\
\text { das revistas, mostrando-se insuficientes para medir a } \\
\text { ciência dos países em desenvolvimento. }\end{array}$ \\
\hline $\begin{array}{l}\text { Bicalho- } \\
\text { Moreira e } \\
\text { Ferreira } \\
(2000)\end{array}$ & $\begin{array}{l}\text { Dificuldade de ponderar } \\
\text { as avaliações e a } \\
\text { atribuição de pesos às } \\
\text { publicações } \\
\text { provenientes de áreas } \\
\text { distintas da ciência. }\end{array}$ & $\begin{array}{l}\text { Na maioria das vezes as avaliações são lineares, entre as } \\
\text { diferentes áreas de conhecimento, sem considerar as } \\
\text { especificidades de cada uma. Há dificuldades e objetivos } \\
\text { diferentes em cada área da ciência, o que leva a níveis } \\
\text { diferenciados de interesse em publicar artigos científicos. } \\
\text { Deve-se considerar a maturidade da área, o que } \\
\text { normalmente leva a que haja muitas opções de periódicos } \\
\text { se já está consolidada mundialmente, facilitando assim a } \\
\text { publicação dos resultados pelos pesquisadores. Deve-se } \\
\text { observar ainda a natureza da área, sua forma de } \\
\text { desenvolvimento das atividades, pois em muitas áreas, } \\
\text { embora já consolidadas, o trabalho é aplicado ou mais } \\
\text { técnico, exigindo outro tipo de envolvimento e outro } \\
\text { resultado a ser apresentado que não o paper. }\end{array}$ \\
\hline $\begin{array}{l}\text { Bicalho- } \\
\text { Moreira e } \\
\text { Ferreira } \\
(2000)\end{array}$ & $\begin{array}{l}\text { Dificuldade de ponderar } \\
\text { as disparidades } \\
\text { socioeconômicas, } \\
\text { culturais e de interesses }\end{array}$ & $\begin{array}{l}\text { Existem disparidades socioeconômicas e culturais, que não } \\
\text { são levadas em consideração. Cientistas que residem em } \\
\text { países subdesenvolvidos realizam suas atividades em } \\
\text { condições distintas daquelas disponíveis nos países mais }\end{array}$ \\
\hline
\end{tabular}




\begin{tabular}{|l|l|l|}
\hline & $\begin{array}{l}\text { de pesquisadores que } \\
\text { residem em localizações } \\
\text { muito distintas. }\end{array}$ & $\begin{array}{l}\text { desenvolvidos. Por vezes, eles têm objetivos específicos de } \\
\text { trabalho que não são do interesse de grandes revistas de } \\
\text { circulação internacional, por estarem relacionados a temas } \\
\text { de interesse regional. }\end{array}$ \\
\hline $\begin{array}{l}\text { Valério } \\
(1994)\end{array}$ & $\begin{array}{l}\text { Qualidade das revistas } \\
\text { nacionais }\end{array}$ & $\begin{array}{l}\text { Outro aspecto a ser observado concerne à qualidade das } \\
\text { revistas produzidas no Brasil. Embora de boa qualidade, } \\
\text { poucas se enquadram no padrão internacional de modo } \\
\text { que possam ser fontes para alimentação de bases de } \\
\text { dados internacionais ou que possam fazer parte de índices } \\
\text { de citação. }\end{array}$ \\
\hline
\end{tabular}

Fonte: Elaborado com base na revisão da literatura especializada.

Em suma, o referencial teórico buscou abarcar os elementos que estão presentes na literatura acerca do tema indicadores de caracterização e de avaliação de resultados, partindo-se de um conceito macro para as idiossincrasias da academia. Deve-se ressalvar, como limitação, que muito do que foi até então escrito priorizou indicadores empresariais, de desenvolvimento industrial e tecnológico, e de relações cooperativas entre universidades e empresas com pouca atenção às interações entre universidades, ou, ainda, entre programas de pósgraduação distintos, e entre programas de pós-graduação e institutos de pesquisa. Assim, novos elementos poderão ser identificados a partir da análise das interações e experiências investigadas neste estudo.

\section{Procedimentos metodológicos}

O estudo caracteriza-se pelo emprego do método de estudo múltiplo de casos, o qual, segundo Yin (2001), prove evidências mais robustas que o estudo de caso único. A investigação de natureza qualitativa se configura como pesquisa exploratória, tendo em vista o número relativamente baixo de trabalhos existentes sobre a questão da caracterização e proposição de indicadores de avaliação de ações de uma agência de fomento, a Fundação Araucária de Apoio ao Desenvolvimento Científico e Tecnológico do Paraná.

Um exame bibliográfico foi realizado para identificar os possíveis impactos, contribuições e outros elementos que norteiam as interações entre instituições de ensino, pesquisa e extensão. Foram selecionados previamente tais elementos, definidos com base na revisão da literatura especializada. Outros eventuais fatores foram embutidos em questões que buscavam explorar as idiossincrasias das interações e do contexto no qual se encontram inseridas. Tal fato justifica-se, pois

embora o estudo de caso se concentre na maneira como uma pessoa ou grupo de pessoas trata determinados problemas, é importante ter um olhar holístico sobre a situação, pois não é possível interpretar o comportamento humano sem a compreensão do quadro referencial dentro do qual os indivíduos desenvolvem os seus sentimentos, pensamentos e ações (GODOY, 2006, p.121). 
O critério para a seleção dos casos consistiu no edital lançado pela diretoria executiva da Fundação Araucária de Apoio ao Desenvolvimento Cientifico e Tecnológico do Paraná (especificamente a publicação dos resultados da aprovação na $1^{\circ}$ e $2^{\circ}$ chamadas) para solicitação de apoio financeiro para o primeiro e segundo semestres do ano 2008 para o Programa de Apoio Financeiro ao Pesquisador Visitante. Logo, a seleção dos entrevistados foi intencional, tendo como base o programa referenciado.

Assim, foram selecionados dez casos, sendo sete deles relacionados à vinda de pesquisadores para programas situados nas universidades e três relacionados à vinda de pesquisadores para institutos de pesquisa. Foram estudados todos os nove casos da primeira chamada do edital e um caso da segunda chamada. $O$ fato de terem sido selecionados os projetos submetidos ao mesmo edital justifica-se, pois todos os casos estiveram sujeitos às mesmas regras, o que, de certa forma, auxilia no estabelecimento de comparações, e reforça os resultados finais da pesquisa.

Com o conhecimento do edital, a investigação percorreu o seguinte caminho: a) Visitas às instituições receptoras localizadas em diversas cidades do Paraná (Londrina, Ponta Grossa, Maringá, Paranavaí e Curitiba); b) Visitas aos locais de trabalho onde os projetos submetidos e aprovados estavam sendo desenvolvidos; c) Entrevistas pessoais com os coordenadores dos projetos, com os pesquisadores visitantes e com outras pessoas envolvidas (quando havia condições de agregar informações relevantes). Foram realizadas 23 entrevistas, sendo dois roteiros semiestruturados - um para o coordenador do projeto e outro para o pesquisador visitante - desenvolvidos inicialmente; d) Observação direta do desenvolvimento de alguns projetos; e) Leitura de documentos secundários que foram adquiridos durante a coleta de dados primários; f) Leitura dos projetos aprovados; g) Novo contato com os entrevistados para esclarecer eventuais dúvidas.

A coleta de dados ocorreu entre setembro de 2008 e janeiro de 2009. Com relação à perspectiva temporal, a pesquisa se enquadra como transversal com corte longitudinal, pois foram abordados, durante as entrevistas, temas e fatos passados que melhoram a compreensão do contexto atual. O nível de análise da pesquisa é relacional, uma vez que o foco está na relação cooperativa estabelecida. Assim sendo, a unidade de análise refere-se ao programa de professor visitante em si. Para a análise e interpretação dos dados foi utilizada a análise de conteúdo.

\section{Contextualização do edital e dos casos}

O edital que serviu de base para a seleção dos casos tinha por propósito

incentivar a realização de visitas de curta e média duração (6 a 12 meses, com possibilidade de renovação por até 12 meses) às instituições públicas e privadas sem fins lucrativos de Ensino Superior e aos institutos de pesquisa de caráter público do Paraná, de pesquisadores, preferencialmente estrangeiros, cuja formação e experiência profissional representem uma contribuição inovadora aos cursos de pós-graduação 
stricto sensu e à consolidação de grupos de pesquisa sediados no Paraná (FUNDAÇÃO ARAUCÁRIA, 2008).

Segundo o edital, foram definidos alguns pontos para identificar aqueles pesquisadores que estariam enquadrados em uma das duas modalidades de pesquisador visitante: (1) Pesquisador visitante sênior e (2) Pesquisador visitante recém-doutor. Entre os critérios selecionados para esta diferenciação, destaca-se a questão do tempo de titulação e da produção científica.

Com relação aos projetos submetidos, estes foram julgados de acordo com alguns critérios apresentados no quadro a seguir.

Quadro 2. Critérios de julgamento dos projetos submetidos.

Critério: Quanto à natureza da instituição receptora do pesquisador visitante

(1) Cursos ou programas de pós-graduação de instituições públicas estaduais de ensino superior do Paraná.

(2) Institutos de pesquisa do estado de caráter público.

(3) Cursos ou programas de pós-graduação das demais instituições de ensino do Estado.

Critério: Quanto à avaliação do curso de pós-graduação receptor do pesquisador visitante

(1) Cursos com notas 3,0 na CAPES/MEC.

(2) Cursos com notas 4,0 na CAPES/MEC.

(3) Cursos com notas 5,0 na CAPES/MEC.

Critérios: Quanto às características da proposta

(1) Relevância do plano de trabalho proposto considerando o seu impacto na área, no programa de pós-graduação, na instituição e no estado.

(2) Importância das metas e atividades previstas no plano de trabalho e no projeto de pesquisa para o crescimento, fortalecimento ou consolidação do curso ou programa de pós-graduação: resultados esperados.

(3) Produção científica do candidato, regular e compatível com a modalidade de apoio solicitado e com o plano de trabalho.

(4) Experiência do candidato na linha de pesquisa proposta.

(5) Viabilidade do plano de trabalho, considerando a infra estrutura disponível no programa de pós-graduação e o período de vigência da bolsa solicitada.

Fonte: Edital da Fundação Araucária- Programa de Apoio ao Pesquisador Visitante (2008).

Os casos que foram analisados neste estudo são apresentados a seguir. $O$ tempo de execução dos projetos e de permanência de pesquisador visitante variou de quatro a doze meses, sendo os projetos aprovados pelo edital pertencentes a diversas áreas do conhecimento. Com relação a esse fato, vale acrescer que não foi possível, somente por meio das entrevistas e coleta de documentos secundários, elucidar e enumerar todos os frutos de cada projeto, uma vez que estes possuíam características diversas, algumas altamente peculiares a uma ou outra área de conhecimento. 
Quadro 3. Apresentação dos casos e das propostas estudadas.

\begin{tabular}{|c|c|c|c|}
\hline $\begin{array}{c}\text { Programa de } \\
\text { pós- } \\
\text { graduação/IP }\end{array}$ & Título do projeto & $\begin{array}{c}\text { Atividades envolvidas para o pesquisador } \\
\text { visitante na interação }\end{array}$ & $\begin{array}{l}\text { Tempo de } \\
\text { visita }\end{array}$ \\
\hline $\begin{array}{l}\text { Engenharia } \\
\text { Elétrica e } \\
\text { Informática } \\
\text { Industrial. } \\
\text { Universidade } \\
\text { Federal } \\
\text { Tecnológica do } \\
\text { Paraná (UTFPR) }\end{array}$ & $\begin{array}{l}\text { "Aplicações médicas da } \\
\text { física nuclear: tomografia } \\
\text { por feixe de prótons" }\end{array}$ & $\begin{array}{l}\text { - desenvolvimento do projeto; } \\
\text { - redação de dois artigos para eventos e três } \\
\text { para periódicos internacionais; }\end{array}$ & $\begin{array}{l}\text { Doze } \\
\text { meses }\end{array}$ \\
\hline $\begin{array}{l}\text { Matemática } \\
\text { Aplicada. } \\
\text { Universidade } \\
\text { Federal do } \\
\text { Paraná (UFPR) }\end{array}$ & $\begin{array}{l}\text { "Computação científica e } \\
\text { suas aplicações em } \\
\text { energia elétrica" }\end{array}$ & $\begin{array}{l}\text { - lecionar uma disciplina; } \\
\text { - participar de seminários semanais com os } \\
\text { demais integrantes do grupo para discussão do } \\
\text { andamento da pesquisa; } \\
\text { - participar de seminários com alunos; } \\
\text { - promover palestras; } \\
\text { - redigir } 1 \text { ou } 2 \text { artigos científicos para } \\
\text { submissão em periódicos internacionais. } \\
\text { - desenvolvimento do projeto em si. }\end{array}$ & $\begin{array}{l}\text { Um } \\
\text { semestre. }\end{array}$ \\
\hline $\begin{array}{l}\text { Laboratório de } \\
\text { Emissões } \\
\text { Veiculares } \\
\text { (LEME) }\end{array}$ & $\begin{array}{l}\text { "Estudo do desempenho } \\
\text { mecânico e da geração } \\
\text { de emissões em motores } \\
\text { alimentados por biodiesel } \\
\text { e a sua mistura em óleo } \\
\text { diesel" }\end{array}$ & $\begin{array}{l}\text { - nivelamento do grupo a respeito de tema da } \\
\text { combustão por meio de seminários (total de } \\
\text { cinco); } \\
\text { - planejamento do experimento com base nos } \\
\text { prazos, custos, opção do biodiesel e escolha do } \\
\text { motor (desenvolvimento do projeto); } \\
\text { - realização dos testes e análise dos resultados; } \\
\text { - curso para pós-graduação; } \\
\text { - elaboração de um artigo científico para revista } \\
\text { internacional. }\end{array}$ & $\begin{array}{l}\text { Doze } \\
\text { meses. }\end{array}$ \\
\hline $\begin{array}{l}\text { Ciência e } \\
\text { Tecnologia de } \\
\text { Alimentos. } \\
\text { Universidade } \\
\text { Estadual de } \\
\text { Ponta Grossa } \\
\text { (UEPG) }\end{array}$ & $\begin{array}{l}\text { "Amidos de mandioca } \\
\text { modificados por } \\
\text { irradiação UV contínua } \\
\text { em escala-piloto" }\end{array}$ & $\begin{array}{l}\text { - projeto de pesquisa: } \\
\text { - formação de massa critica de trabalho: } \\
\text { capacitação em nível de mestrado, estabelecer } \\
\text { procedimentos e objetivos de metodologias, } \\
\text { promover um seminário sobre o setor } \\
\text { agroindustrial; } \\
\text { - apresentação dos resultados obtidos no projeto } \\
\text { a técnicos do setor privado, promoção de } \\
\text { discussões e avaliação da possibilidade de } \\
\text { transferência dessa tecnologia; } \\
\text { - realizar palestras e visitas técnicas; } \\
\text { - interações e divulgação dos resultados com } \\
\text { submissão de dois artigos em periódicos e dois } \\
\text { para congressos; } \\
\text { - promoção de intercâmbio de docentes e } \\
\text { discentes do programa receptor e do programa } \\
\text { de origem do pesquisador. }\end{array}$ & $\begin{array}{l}\text { Quatro } \\
\text { meses. }\end{array}$ \\
\hline $\begin{array}{l}\text { Psicologia. } \\
\text { Universidade } \\
\text { Estadual de } \\
\text { Maringá (UEM) }\end{array}$ & $\begin{array}{l}\text { "Epistemologia da } \\
\text { psicologia". }\end{array}$ & $\begin{array}{l}\text { - desenvolvimento do projeto de pesquisa; } \\
\text { - participação em grupos de pesquisa dos } \\
\text { professores do programa; } \\
\text { - docência em uma disciplina; } \\
\text { - redação de um artigo científico para revista } \\
\text { internacional; } \\
\text { - organização de um congresso internacional. }\end{array}$ & $\begin{array}{l}\text { Doze } \\
\text { meses. }\end{array}$ \\
\hline $\begin{array}{l}\text { IAPAR . Instituto } \\
\text { Agronômico do } \\
\text { Paraná (sede de } \\
\text { Londrina) }\end{array}$ & $\begin{array}{l}\text { "Caracterização } \\
\text { fenológica e fisiológica } \\
\text { da videira 'RBS Carmen' } \\
\text { visando à viabilização } \\
\text { para processamento } \\
\text { industrial no norte do } \\
\text { Paraná" }\end{array}$ & $\begin{array}{l}\text { - desenvolvimento do projeto; } \\
\text { - redação de dois artigos científicos para revistas } \\
\text { internacionais; } \\
\text {-orientação dos produtores locais de uva e } \\
\text { laranja; }\end{array}$ & $\begin{array}{l}\text { Doze } \\
\text { meses. }\end{array}$ \\
\hline $\begin{array}{l}\text { Matemática } \\
\text { Aplicada e } \\
\text { Computacional. } \\
\text { Universidade } \\
\text { Estadual de } \\
\text { Londrina (UEL) } \\
\end{array}$ & $\begin{array}{l}\text { "Controle ótimo, } \\
\text { sistemas dissipativos e } \\
\text { aplicações" }\end{array}$ & $\begin{array}{l}\text { - docência em uma disciplina e trabalho como } \\
\text { colaborador em outra; } \\
\text { - desenvolvimento do projeto de pesquisa; } \\
\text { - realização de seminários semanais com grupos } \\
\text { de pesquisa; } \\
\text { - organização de um evento na área; }\end{array}$ & $\begin{array}{l}\text { Um } \\
\text { semestre. }\end{array}$ \\
\hline
\end{tabular}




\begin{tabular}{|c|c|c|c|}
\hline & & $\begin{array}{l}\text { - redação de dois artigos científicos para revista } \\
\text { internacional; }\end{array}$ & \\
\hline $\begin{array}{l}\text { Agronomia. } \\
\text { Universidade } \\
\text { Estadual de } \\
\text { Londrina (UEL) }\end{array}$ & $\begin{array}{l}\text { "Caracterização } \\
\text { molecular e enzimática } \\
\text { de fungos de interesse } \\
\text { agronômico" }\end{array}$ & $\begin{array}{l}\text { - desenvolvimento do projeto; } \\
\text { - supervisão de grupos de pesquisa no } \\
\text { laboratório; } \\
\text { - lecionar uma disciplina; } \\
\text { - redação de três trabalhos científicos para } \\
\text { revista internacional; } \\
\text { - auxílio na co-orientação de alunos de mestrado } \\
\text { e doutorado; }\end{array}$ & $\begin{array}{l}\text { Doze } \\
\text { meses. }\end{array}$ \\
\hline $\begin{array}{l}\text { IAPAR. Instituto } \\
\text { Agronômico do } \\
\text { Paraná (estação } \\
\text { de Paranavaí) }\end{array}$ & $\begin{array}{l}\text { "Desempenho animal e } \\
\text { respostas agronômicas e } \\
\text { morfológicas de Panicum } \\
\text { maximum jacq.cv. } \\
\text { milênio em função da } \\
\text { adubação nitrogenada, } \\
\text { manejado com 95\% de } \\
\text { interceptação luminosa" }\end{array}$ & $\begin{array}{l}\text { - desenvolvimento do projeto; } \\
\text { - redação de dois artigos com os resultados } \\
\text { parciais da pesquisa e um artigo com os } \\
\text { resultados finais; } \\
\text { - orientação prática aos pecuaristas locais; }\end{array}$ & $\begin{array}{l}\text { Doze } \\
\text { meses. }\end{array}$ \\
\hline $\begin{array}{l}\text { Gestão do } \\
\text { território. } \\
\text { Universidade } \\
\text { Estadual de } \\
\text { Ponta Grossa } \\
\text { (UEPG) }\end{array}$ & $\begin{array}{l}\text { "Economia das } \\
\text { convenções e sistemas de } \\
\text { governança: uma análise } \\
\text { a partir da complexidade } \\
\text { das comunidades de } \\
\text { faxinais" }\end{array}$ & $\begin{array}{l}\text { - desenvolvimento do projeto de pesquisa; } \\
\text { - docência em dois cursos de curta duração para } \\
\text { os alunos das linhas de pesquisa do programa. } \\
\text { - promoção de seis palestras em outras } \\
\text { universidades do estado; } \\
\text { - submissão de um artigo científico a um } \\
\text { periódico nacional e um internacional. }\end{array}$ & $\begin{array}{l}\text { Quatro } \\
\text { meses. }\end{array}$ \\
\hline
\end{tabular}

Fonte: Elaboração com base na coleta de dados primários.

Foi observado nos casos estudados que, devido ao edital já ter como exigência para submissão o estabelecimento de objetivos claros para os projetos, todas as propostas aprovadas possuíam objetivos específicos a serem atingidos e, portanto, as suas cooperações se caracterizavam como "acordos formais com alvos definidos" (BONACCORSI; PICCALUGA, 1994). No tocante à estrutura de interface (SEGATTO, 1996), para intermediação e gestão dos recursos, nas universidades federais observou-se a presença das fundações; nas universidades estaduais, das pró-reitorias; e nos institutos de pesquisa, a gestão dos recursos ficava sob a responsabilidade do próprio instituto.

Com relação aos recursos que possibilitaram a vinda dos visitantes, em todos os casos o recurso foi liberado pela Fundação Araucária, cumprindo a sua função de agência de fomento pela lei de inovação (Lei n. 10.973, de 2 de dezembro de 2004). Nenhum programa ou instituto de pesquisa apresentou contrapartida financeira em termos de desembolso. Com relação aos programas, as contrapartidas se referiram ao uso da estrutura da instituição, bibliotecas, computadores, laboratórios e salas de aula. Por meio das entrevistas, foi observado que alguns dos coordenadores tinham outras ambições com relação ao melhor aproveitamento da presença de um pesquisador externo no seu programa, contudo tais intenções não se concretizaram por conta da falta de disponibilidade de recursos que as viabilizassem.

No caso dos institutos de pesquisa, verificou-se que estes, embora não tenham apresentado contrapartidas em termos de desembolso financeiro em seus projetos (análise dos documentos secundários), estavam despendendo uma quantia de recursos acima de $\mathrm{R} \$ 150$ mil - em equipamentos e outros insumos para as suas pesquisas - para manter os projetos em execução.

Com relação à duração dos projetos, vale afirmar que, da maneira como estava sendo desenvolvido e tendo em vista o rigor que cada área de 
conhecimento demanda para que os resultados encontrados sejam válidos, pode ser necessário que alguns programas e institutos de pesquisa solicitem a prorrogação das atividades do pesquisador visitante, respeitando o limite de meses estabelecido no edital.

\section{Proposta de Indicadores de Resultados para interações de Pesquisadores Visitante e Instituições de Ensino e Pesquisa}

Tendo em vista as possibilidades de se definirem indicadores que orientem a identificação dos resultados das interações aqui estudadas, cabe fazer, de início, um resgate da teoria sobre o tema, observando indicadores já estabelecidos que sejam pertinentes para o presente trabalho, considerando as idiossincrasias das interações observadas e o caráter interdisciplinar dos projetos, fato que - por si só - elimina a possibilidade de uma proposta de indicadores de resultados restrita à avaliação exclusiva - por exemplo - das publicações realizadas.

Deve-se ressalvar, porém, que não se pretende transformá-los em critérios definitivos para o julgamento de uma pesquisa, especialmente por tratar-se de indicadores cuja relevância deve respeitar o contexto da pesquisa e a especificidade do conhecimento científico em desenvolvimento, pois cada área possui certas características e critérios quanto à relevância de uma pesquisa, suas contribuições para a construção do conhecimento científico, bem como a perspectiva temporal para conferir a confiabilidade/credibilidade dos achados.

Sob esta ótica, a análise de indicadores procurou ater-se às disparidades das realidades e das circunstâncias em que os projetos são desenvolvidos, bem como as especificidades de cada área do conhecimento. Como são áreas distintas, é possível afirmar que o tempo necessário de pesquisa e o tempo requerido de reflexão e repercussão podem ir além do prazo do edital para apresentação de resultados. Logo, a sugestão de conciliar mais de um tipo de indicador faz-se necessária.

Os elementos encontrados durante a coleta de dados, observações no campo, visitas às instituições receptoras dos pesquisadores visitantes e a leitura e análise dos dados secundários permitiram a seleção de alguns elementos, próprios do tipo de interação de pesquisa conjunta que se estava investigando. A seguir, são apresentados tais elementos:

1. Redução no tempo de obtenção de resultados previstos;

2. Relatórios de pesquisa;

3. Orientações e co-orientações - de graduação, mestrado e doutorado - em andamento;

4. Orientações e co-orientações - de graduação, mestrado e doutorado concluídas;

5. Participação em bancas;

6. Incremento na participação dos alunos nos grupos de pesquisa; 
7. Disciplinas, cursos de curta duração e palestras ministradas pelo pesquisador visitante;

8. Elevação do número de matrículas de alunos nas disciplinas ministradas por professores visitantes;

9. Treinamento e aperfeiçoamento de pesquisadores (especialmente nos institutos de pesquisa);

10. Propostas de alteração curricular;

11. Intercâmbio entre alunos das instituições;

12. Artigos submetidos (eventos nacionais, eventos internacionais, periódicos nacionais, periódicos internacionais);

13. Publicações já realizadas (artigos em periódicos; anais de eventos; capítulos de livro; livro; artigos em jornais)

14. Número de referências a publicações oriundas da pesquisa cooperativa;

15. Programas computacionais em desenvolvimento a partir da interação;

16. Programas computacionais desenvolvidos a partir da interação;

17. Produtos ou processos com pedido de patente;

18. Patentes concedidas e produtos licenciados;

19. Continuidades do projeto;

20. Novas interações entre pesquisadores das instituições;

21. Contrapartidas financeiras da instituição receptora para a execução do projeto;

22. Formação de convênios formais de cooperação a partir do projeto;

23. Impactos comerciais;

24. Impactos para as comunidades locais onde a pesquisa foi realizada.

A partir dos indicadores sugeridos, um roteiro para caracterização da interação pode ser proposto no quadro a seguir.

Quadro 5. Proposta de indicadores para caracterização e avaliação de cooperações

I- Caracterização da Interação:

\begin{tabular}{|c|c|c|c|c|c|c|c|c|c|c|}
\hline \multirow[b]{2}{*}{ Atores envolvidos } & \multicolumn{10}{|c|}{ Participantes } \\
\hline & $\begin{array}{l}\text { Univ. } \\
\text { Nacional }\end{array}$ & \multicolumn{2}{|c|}{$\begin{array}{l}\text { Univ. } \\
\text { Internac }\end{array}$} & \multicolumn{2}{|c|}{$\begin{array}{l}\text { Prog. isolados } \\
\text { pós-graduação }\end{array}$} & \multicolumn{2}{|c|}{$\begin{array}{l}\text { Inst. de } \\
\text { pesquisa }\end{array}$} & $\begin{array}{l}\text { Empresas } \\
\text { públicas }\end{array}$ & $\begin{array}{c}\text { Empresas } \\
\text { privadas }\end{array}$ & Outro \\
\hline \multicolumn{11}{|l|}{ Doutores } \\
\hline \multicolumn{11}{|l|}{ Alunos de Doutorado } \\
\hline \multicolumn{11}{|l|}{ Mestres } \\
\hline \multicolumn{11}{|l|}{ Alunos de Mestrado } \\
\hline \multicolumn{11}{|l|}{ Especialistas } \\
\hline \multicolumn{11}{|l|}{ Graduados } \\
\hline \multirow{2}{*}{\multicolumn{11}{|c|}{ Alunos de Graduação }} \\
\hline \multirow[b]{2}{*}{$\begin{array}{c}\text { Áreas de conhecimento envolvidas (exemplo } \\
\text { hipotético, deve envolver as áreas da } \\
\text { cooperação) }\end{array}$} & & & & & & & & & & \\
\hline & \multicolumn{2}{|c|}{$\begin{array}{l}\text { Puramente } \\
\text { acadêmica }\end{array}$} & \multicolumn{2}{|c|}{$\begin{array}{l}\text { Acadêmica } \\
\text { aplicabilidade } \\
\text { prática }\end{array}$} & \multicolumn{2}{|c|}{$\begin{array}{l}\text { Puramente de } \\
\text { aplicabilidade } \\
\text { prática }\end{array}$} & \multicolumn{2}{|c|}{$\begin{array}{c}\text { Aplicabilidade prática } \\
\text { com possibilidades } \\
\text { de patentes }\end{array}$} & \multicolumn{2}{|c|}{$\begin{array}{l}\text { Aplicabilidade prática com } \\
\text { possibilidades comerciais }\end{array}$} \\
\hline \multicolumn{11}{|l|}{ Matemática e Computação } \\
\hline \multicolumn{11}{|l|}{ Agronomia e Biologia } \\
\hline Geografia e Economia & & & & & & & & & & \\
\hline
\end{tabular}


Continuação

\begin{tabular}{|l|l|l|l|l|}
\hline \multicolumn{2}{|c|}{ Recursos envolvidos } \\
\hline & Tnstituição receptora & Edital & Origem dos recursos \\
\hline Recursos financeiros & & & & \\
\hline Equipamentos & & & & \\
\hline Material de consumo & & & & \\
\hline Área da pesquisa/experimento & & & & \\
\hline Laboratórios & & & & \\
\hline
\end{tabular}

II - Indicadores dos resultados:

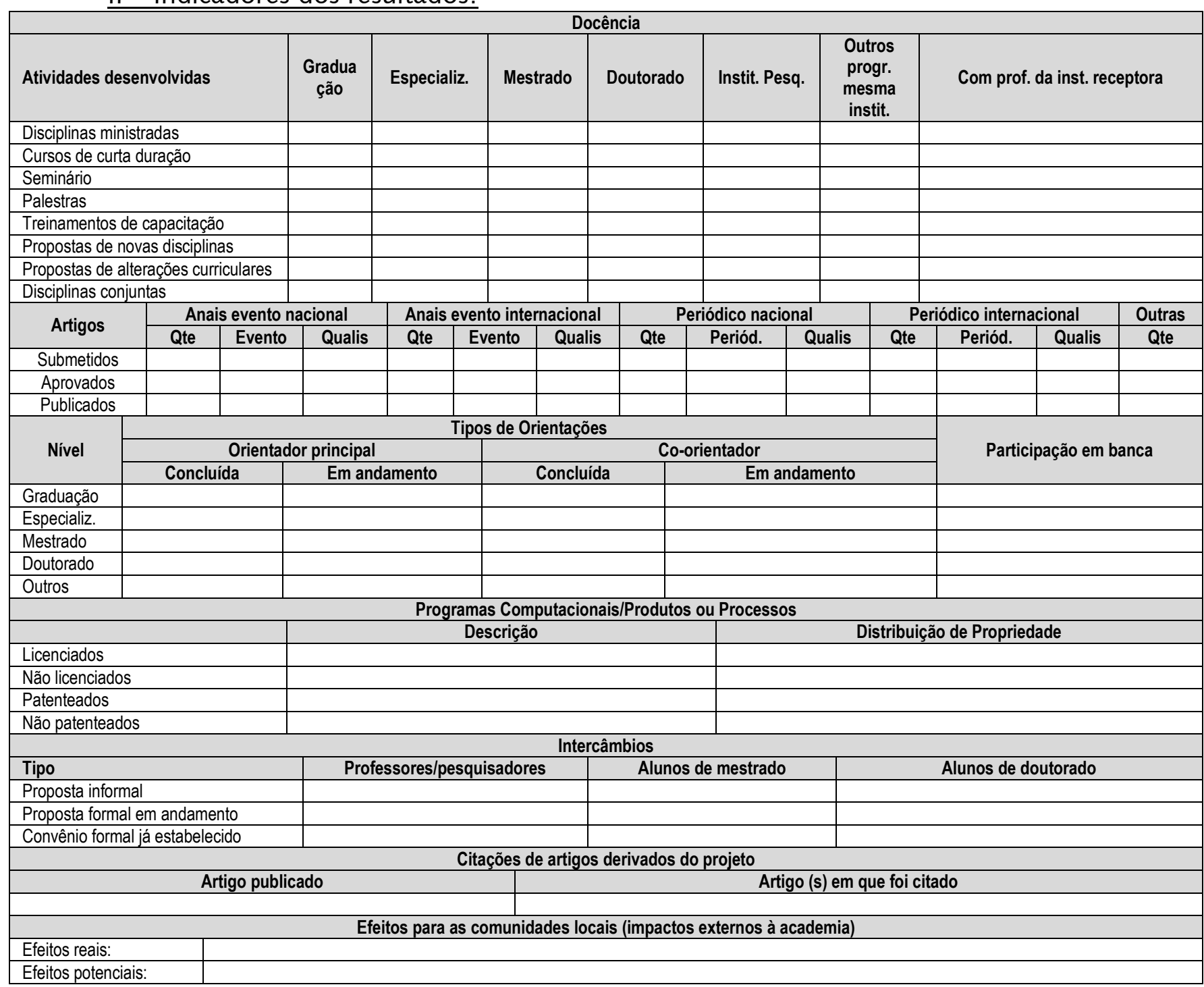

Fonte: Elaborado com base na revisão da literatura e coleta de dados.

Com os elementos contidos no Quadro 5, procura-se retratar de modo próximo à realidade os projetos conjuntos, bem como suas peculiaridades, dentro do contexto das pesquisas cooperativas interdisciplinares entre pesquisadores de diferentes universidades e institutos de pesquisa. Com essas informações em mãos, poder-se-ia promover o ajuste de futuros editais e estabelecer comparações entre projetos abarcadas neste tipo de cooperação. 


\section{Considerações finais}

O presente estudo procurou definir uma proposta de indicadores de resultados para interações de pesquisadores visitantes e instituições de ensino e pesquisa. O estudo realizado a partir de um edital lançado por uma agência de fomento estadual, promovendo um programa de apoio financeiro para o intercâmbio de pesquisadores/professores visitantes entre universidades e institutos de pesquisa, permitiu observar, durante a investigação, a possibilidade de indicadores distintos daqueles usualmente presentes no meio acadêmico e na literatura especializada.

A pesquisa, do ponto de vista teórico, contribui com o desenvolvimento de uma proposta de indicadores para caracterização e avaliação de cooperações interdisciplinares entre pesquisadores de universidades e institutos de pesquisa distintos. Já entre as contribuições práticas, o auxílio a instituições de fomento no aperfeiçoamento de editais de apoio ao desenvolvimento científico (como os de intercâmbio de professores) é um dos resultados que podem ser mencionados: se instrumentos de avaliação de tais iniciativas forem desenvolvidos a partir de pesquisas empíricas, e, posteriormente, aperfeiçoados, as próprias agências poderão analisar o retorno e a eficiência das suas ações. Assim, poder-se-ia aprofundar o conhecimento do uso prático dos recursos destinados a esse tipo de programa e averiguar a possibilidade de adoção de mecanismos de avaliação dessas ações de fomento.

Adicionalmente, futuras pesquisas nesta temática podem incrementar o conhecimento deste tipo de relação interinstitucional (entre pesquisadores de universidades distintas), ainda pouco pesquisado e considerado como fator de elevação potencial do conhecimento e das capacidades e competências de grupos de pesquisa, laboratórios, programas de pós-graduação stricto sensu ou universidades. Isso pode ocorrer tanto por meio do compartilhamento do conhecimento entre os participantes como na forma da contribuição momentânea dos pesquisadores visitantes em universidades e institutos de pesquisa e os impactos das cooperações realizadas por meio dessas visitas.

Por fim, algumas limitações da pesquisa, resultantes do seu método ou da periodicidade disponível à sua coleta, precisam ser colocadas, tais como: a impossibilidade de generalização dos achados e o tempo disponível para coleta.

\section{REFERÊNCIAS}

AGUIAR, A.C. Percepções de pesquisadores sobre atividades cooperativas de P\&D: uma análise com base na teoria institucional. Revista de Administração Contemporânea, v.11, n.4, 2007, p.59-86.

ALBUQUERQUE, E. M.; SIMÕES, R.; BAESSA, A.; CAMPOLINA, B.; SILVA, L. A distribuição espacial da produção científica e tecnológica brasileira: uma descrição de estatísticas de produtividade local de patentes e artigos científicos. Revista Brasileira de Inovação, v. 1, n. 2, p. 225-251, jul./dez. 2002. 
ANPED - Associação Nacional de Pós-Graduação e Pesquisa em Educação. Documento sobre o Programa de Intercâmbio, 1984.

BABBIE, Earl. The practice of social research. 6. ed, Belmont, CA: Wadsworth, 1992.

BICALHO-MOREIRA, L. M.; FERREIRA, M. A. T. Inovação tecnológica na universidade: representação nos indicadores de ciência e tecnologia. In: Anais do Simpósio de Gestão da Inovação Tecnológica. São Paulo, 2000.

BRASIL. Decreto-Lei 10.973, de 2 de dezembro de 2004. Dispõe sobre incentivos à inovação e à pesquisa científica no ambiente produtivo, e dá outras providências. Brasília, DF: Diário Oficial da República Federativa do Brasil, 2004.

BRISOLLA, S. N. Indicadores de Ciência, Tecnologia e Inovação no Brasil. Revista Brasileira de Inovação, v. 3, n. 1, p. 213-225, 2004.

CYERT, R. M. e GOODMAN, P. S. Creating effective university-industry alliances: an organizational learning perspective. Organizational Dynamics, v. 25, n. 4. p. 45-57, 1997.

DOSSA, Alvaro; SEGATTO, Andréa Paula. Pesquisas Cooperativas entre universidades e institutos públicos no setor agropecuário brasileiro. Revista de Administração Pública, v. 44, n. 6, p. 1327-1352, 2010.

FURTADO, A.; QUADROS, R.; QUEIROZ, S. Índice Brasil de Inovação: Projeto tem início com empresas do setor industrial. Revista Inovação Uniemp, São Paulo. 1998. Disponível em: <http://www.labjor.unicamp.br/ibi/index.html>. Acesso em: 20 abr.2008.

FUNDAÇÃO ARAUCÁRIA DE APOIO AO DESENVOLVIMENTO CIENTÍFICO E TECNOLÓGICO DO PARANÁ. Programa de Apoio a Pesquisador Visitante: chamada de projetos 01/2008 e 02/2008. Curitiba, Paraná. Acesso em 03 de outubro de 2008. Disponível em:

http: www.fundacaoaraucaria.org.br/chamadas/chamadas2008/cp01-2008.pdf.

GATTI, B. A. Formação de grupos e redes de intercâmbio em pesquisa educacional: dialogia e qualidade. Revista Brasileira de Educação, n. 30, set./dez. 2005.

HERRLEIN PEREIRA, Claudia Maria. Investimentos em ciência e tecnologia: indicadores de resultados de projetos de pesquisa. 2001. 111f. Dissertação de Mestrado - UFRGS, Escola de Administração, Porto Alegre, 2001.

HAIR JR., Joseph F.; BABIN, Barry; MONEY, Arthur H.; SAMOUEL, Phillip. Fundamentos de métodos de pesquisa em administração. Porto Alegre: Bookman, 2005. 
LASTRES, H. M. M.; LEGEY, R. I.; ALBAGLI, S. Indicadores da economia e sociedade da informação, conhecimento e aprendizado. In: VIOTTI, Eduardo B.; MACEDO, Mariano de Mattos. (Orgs). Indicadores de Ciência, Tecnologia e Inovação no Brasil. São Paulo: Editora da Unicamp, 2003, p. 537-578.

LOURES, C. S.; FIGUEIREDO, P. N. Mensuração de Capacidade Tecnológica no Contexto de Industrialização Recente: Por que é Necessário Ampliar o Foco de Estudos Industriais? In: Simpósio de Gestão da Inovação Tecnológica da ANPAD, 24., 2006, Gramado. Anais do XXIV Simpósio de Gestão da Inovação Tecnológica da ANPAD. Gramado, 2006. 1 CD-ROM.

MARTÍNEZ, Eduardo; ALBORNOZ, Mario. Indicadores de ciencia y tecnologia: balance y perspectivas. In: MARTÍNEZ, Eduardo; ALBORNOZ, Mario (Eds.) Indicadores de ciencia y tecnologia: estado del arte y perspectivas. Caracas: Nueva Sociedad, 1998.

MEZAN, R. O Fetiche da Quantidade. Folha de S. Paulo, Domingo, 09/05/2010. Caderno Folha Mais, p. 3.

MOSTAFA, S. P., MARANON, E. I. M., Os intelectuais e sua produtividade. Ciência da Informação. Brasília, v. 22, n.1, p. 22-29, jan. abr. 1993.

MUSSI, F. B.; SEGATTO, A. P. Análise do Instrumento de Cooperação Interinstitucional - programa de pesquisadores visitantes em instituições de ensino, pesquisa e/ou extensão. In: XXXIV Encontro da ANPAD, 2010, Anais do EnANPAd 2010. Rio de Janeiro: ANPAd, 2010. v. 1. p. 1-15.

NELSON, R. R. National Innovation System. A Comparative Analysis. Nova York: Oxford University Press, 1993.

ROSSONI, L. ; GUARIDO FILHO, E. R. . Cooperação Interinstitucional no Campo da Pesquisa em Estratégia. RAE. Revista de Administração de Empresas, v. 47, p. 72-86, 2007.

ROSSONI, L.; HOCAYEN-DA-SILVA, A. J.; FERREIRA JUNIOR, I. Estrutura de Relacionamento entre Instituições de Pesquisa do Campo de Ciência e Tecnologia no Brasil. RAE. Revista de Administração de Empresas, v. 48, p. 34-48, 2008.

ROSSONI, L.; HOCAYEN-DA-SILVA, A. J. Cooperação entre Pesquisadores da Área de Administração da Informação: Evidências Estruturais de Fragmentação das Relações no Campo Científico. RAUSP. Revista de Administração, v. 43, p. 138151, 2008.

SEGATTO, A. P. Análise do processo de cooperação universidade-empresa: um estudo exploratório. 175f. Dissertação (Mestrado). Departamento de Administração, Universidade de São Paulo, São Paulo, 1996. 
- SBRAGIA, R. O processo de cooperação universidade-empresa em universidades brasileiras. Revista de Administração, São Paulo, v. 37, n. 4, p. 5871, out./dez. 2002.

SPINAK, E. Indicadores cienciométricos. Ciência da Informação, Brasília, v. 27, n. 2, p. 141-148, mai./ago. 1998.

VIOTTI, Eduardo B.; MACEDO, Mariano de Mattos. Indicadores de Ciência, Tecnologia e Inovação no Brasil. Editora da Unicamp, 2003.

YIN, R. K. Estudo de Caso: planejamento e métodos. 3. ed. Porto Alegre: Bookman, 2001.

Submetido em 20/10/2013

Aprovado em 05/12/2014

Sobre os autores

Fabrício Baron Mussi

Mestre em Administração - Área de Tecnologia e Inovação pela Universidade Federal do Paraná. Administrador do Departamento de Reservatório e Áreas Protegidas da Usina Hidrelétrica de Itaipu. E-mail: fmussi@itaipu.gov.br.

\section{Blasius Silvano Debald}

Mestre em Desenvolvimento Regional - Área Sociocultural pela UNISC/RS e Doutorado em Educação pela UNISINOS/PR. Professor do Curso de História da Faculdade União das Américas UNIAMÉRICA/PR.

Endereço: Av. Tarquínio Joslin Santos, 1000, Campus Universitário. 85870400 - Foz do Iguacu, PR - Brasil

E-mail: blasius@uniamerica.br. 